\author{
А. А. Кудреватых, Т. П. Мартьянов, Л. С. Клименко \\ РАЗРАБОТКА ОПТИЧЕСКИХ ХЕМОСЕНСОРОВ \\ ДЛЯ ОБНАРУЖЕНИЯ ЦИАНИД-ИОНОВ В ВОДНЫХ СРЕДАХ
}

Работа выполнена при финансовой поддержке РФФИ и Правительства ХМАО-Югры (проект № 18-43-860005).

С иелью разработки анионных рецепторов для обнаружения двух наиболее важных для окружающей среды анионов - фторида и циианида - были синтезированы новые лиганды на основе 1-гидрокси-2-ачиламиноантрахинонов и изучены их сенсорные свойства. Спектрофотометрическим методом исследованы молекулярные взаимодействия с различными анионами в виде солей тетрабутиламмония в ДМСО и ДМСО-водной смеси. Оказалось, что растворы 1-гидрокси-2-ациламиноантрахинонов в ДМСО, первоначально желтого ивета, становились темно-фиолетовыми при добавлении циианид-, фторид-, фосфат- и ацетат-ионов. Добавление других солей не вызывало изменений в спектрах поглощения. При переходе к водному ДМСО контрастное изменение ивета раствора наблюдалось только при добавлении ичианид-иона. Были определены константы устойчивости комплексов и метрологические характеристики процессов. На основе 1-гидрокси-2-бензоиламиноантрахинона были изготовлены и испытаны колориметрические «тест-полоски» для обнаружения $C N$-ионов в водной среде.

Ключевые слова: колориметрический сенсор, хемосенсор, ичинид-ион, антрахинон.

A. A. Kudrevatykh, T. P. Martyanov, L. S. Klimenko

\title{
DESING OF OPTICAL CHEMOSENSORS FOR DETECTION OF CYANIDE IONS IN WATER ENVIRONMENTS
}

Molecular interactions with various anions in the form of tetrabutylammonium salts in DMSO and DMSO-aqueous mixture were studied spectrophotometrically. It turned out that the solutions of 1-hydroxy-2-acylaminoanthraquinones in DMSO, originally yellow, became dark purple with the addition of cyanide, fluoride, phosphate, and acetate ions. The addition of other salts did not cause changes in the absorption spectra. When switching to aqueous DMSO, a contrasting color change in the solution was observed only with the addition of the cyanide ion. The stability constants of the complexes and the metrological characteristics of the processes were determined. On the basis of 1hydroxy-2-benzoylaminoanthraquinone, colorimetric "test strips" were made and tested for the detection of $\mathrm{CN}$-ions in an aqueous medium.

Keywords: colorimetric sensors, chemosensor, cyanide ion, anthraquinone.

\section{Введение}

Разработка молекулярных рецепторов для обнаружения анионов является предметом интенсивных научных исследований, поскольку анионы присутствуют повсеместно и играют важную роль в различных химических и биологических процессах, в медицине и промышленности [1-4]. Например, фторид-, фосфат-ионы играют важнейшую роль в биологических процессах, однако их избыточное содержание приводит к загрязнению природных объектов, а высокая концентрация ионов фтора в организме может привести к заболеванию флюорозом. Особое внимание уделяется детектированию высокотоксичного цианид-иона. Присутствие цианидов в объектах окружающей среды вызвано их широким промышленным ис- 
пользованием [5]. Ежегодно производится 1.4 млн тонн цианида для нужд горнодобывающей промышленности, металлообработки (отделки и гальванизации), производства пластмасс, производства волокон, косметики, фотографии, фармацевтики, борьбы с вредителями и пищевой промышленности. Безусловно, разработка простых и доступных методов обнаружения токсичных анионов является актуальной задачей, для решения которой используются флуоресцентные и колориметрические сенсоры, позволяющие проводить их обнаружение невооруженным глазом [6-8].

Согласно литературным данным $[1,11]$, колориметрический сенсор строится путем объединения хромофора и блока связывания анионов (схема 1). Во многих случаях связывание анионов осуществляется донорами Н-связи $(\mathrm{OH}, \mathrm{NH})$. Взаимодействие с аналитом индуцирует внутримолекулярный перенос заряда (ВПЗ) и приводит к изменению электронного спектра поглощения хромофора. Селективность анионного сенсора связана как со структурой хромофора, так и с основностью анионов. Среди анионов $\mathrm{F}^{-}$является наиболее электроотрицательным атомом, поэтому при взаимодействии с рецепторными группами $(\mathrm{NH}, \mathrm{OH})$ происходят процессы ассоциации с атомами водорода вплоть до депротонирования [12]. В качестве сигнальной части в колориметрических анионных сенсорах широко используются коммерчески доступные производные хинонов, ковалентно присоединенные к анионному рецептору [13].

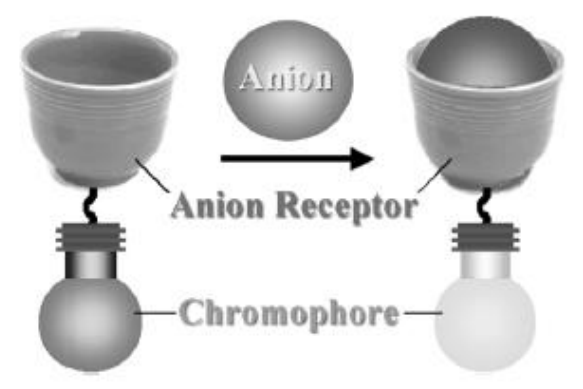

Схема 1 - Устройство колориметрического сенсора

В данной работе исследуются свойства новых молекулярных сенсоров на основе производных антрахинона для определения двух наиболее важных для окружающей среды анионов - фторида и цианида. Производные антрахинона являются важнейшими аналитическими реагентами, широко применяемыми в качественном и количественном анализе. При этом используется способность $\alpha$-гидрокси- и $\alpha$-аминоантрахинонов образовывать с различными элементами окрашенные комплексные соединения и соли [14]. Современным направлением использования различных производных антрахинона является создание на их основе колориметрических сенсоров на различные катионы и анионы [3].

\section{Обсуждение полученных результатов}

С целью разработки новых анионных рецепторов нами были синтезированы 1-гидрокси-2ациламино-9,10-антрахиноны и изучены их сенсорные свойства. Эти соединения были получены нами в одну стадию из коммерчески доступного 1-гидрокси-2-амино-9,10-антрахинона. В качестве ацилирующих агентов были использованы ангидриды уксусной и трифторуксусной кислот, а также бензоил- и пентафторбензоилхлориды. Структуры синтезированных соединений S1-S4 подтверждены комплексом спектроскопических методов анализа.

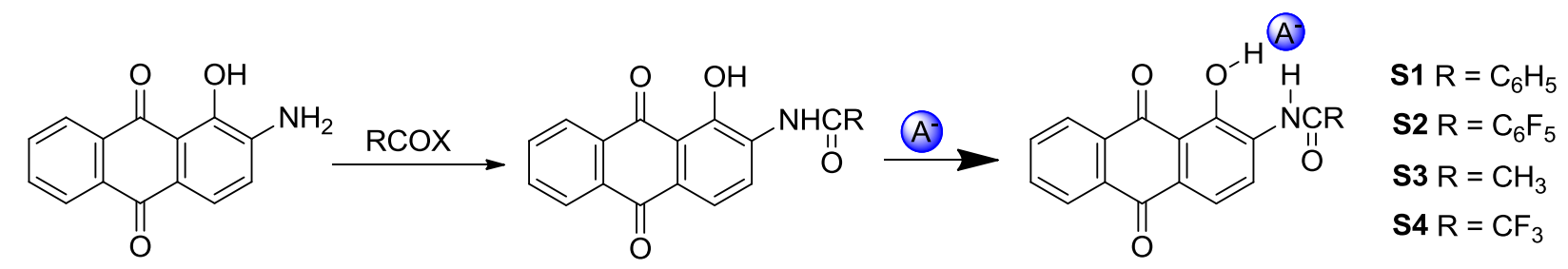


Изучение анион-рецепторных свойств растворов полученных соединений проводили спектрофотометрическим методом. Исследования проводили как в органической среде ( $\mathrm{MeOH}, \mathrm{MeCN}$ и ДМСO), так и в водно-органических средах (50\% и $20 \%$ по объему). В качестве аналитов были испытаны следующие анионы: $\mathrm{CN}^{-}, \mathrm{F}^{-}, \mathrm{AcO}^{-}, \mathrm{H}_{2} \mathrm{PO}_{4}^{-}, \mathrm{Cl}^{-}, \mathrm{Br}^{-}, \mathrm{I}^{-}, \mathrm{HSO}_{4}{ }^{-}$ $\mathrm{NO}_{3}{ }^{-}$и $\mathrm{SCN}^{-}$в виде солей тетрабутиламмония фирмы «Sigma-Aldrich». Было обнаружено, что растворы в ДМСО первоначально желтого цвета $\left(\lambda_{\max }=430\right.$ нм $)$ становились темнофиолетовыми $\left(\lambda_{\max }=545\right.$ нм) при добавлении цианид-, фторид-, фосфат- и ацетат-ионов. При добавлении других анализируемых аналитов никаких изменений в спектрах поглощения нами не наблюдалось (рисунок 1).

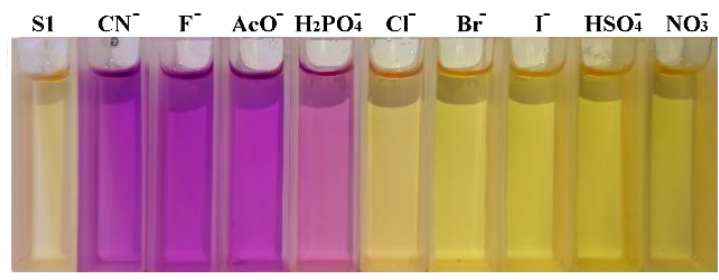

Рисунок 1 - Изменение цвета растворов S1 в ДМСО при добавлении солей ТБА

Чтобы оценить сенсорные свойства S1-S4 в водной среде, были исследованы растворы в $50 \%$ водном ДМСО. Оказалось, что только при добавлении цианид-иона сохраняется значительное батохромное смещение длинноволновой полосы поглощения ( $\Delta \lambda=115$ нм), что выражается в контрастном изменении цвета раствора (рисунок 2). Предел обнаружения цианидионов невооруженным глазом составил $10 \mu \mathrm{M}$.

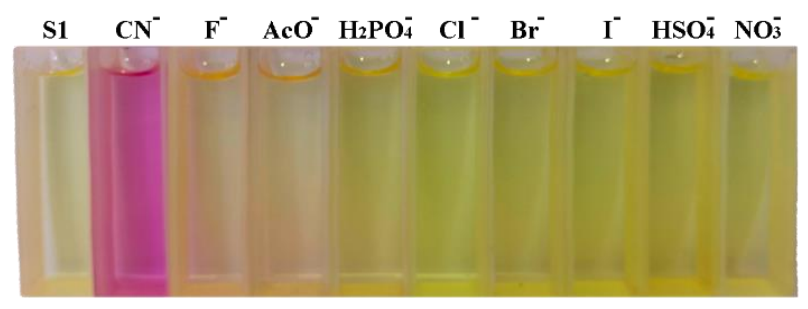

Рисунок 2 - Изменение цвета растворов S1 в 50 \% водном ДМСО при добавлении солей ТБА

Методом спектрофотометрического титрования были определены константы устойчивости комплексов и метрологические характеристики процессов. Добавление цианида ТБА к водно-ацетонитрильному (5 \% $\mathrm{H}_{2} \mathrm{O}$ ) раствору соединения $\mathbf{S 1}$ приводит к падению интенсивности длинноволновой полосы поглощения (427 нм) и появлению новой полосы с максимумом 523 нм (рисунок 3).

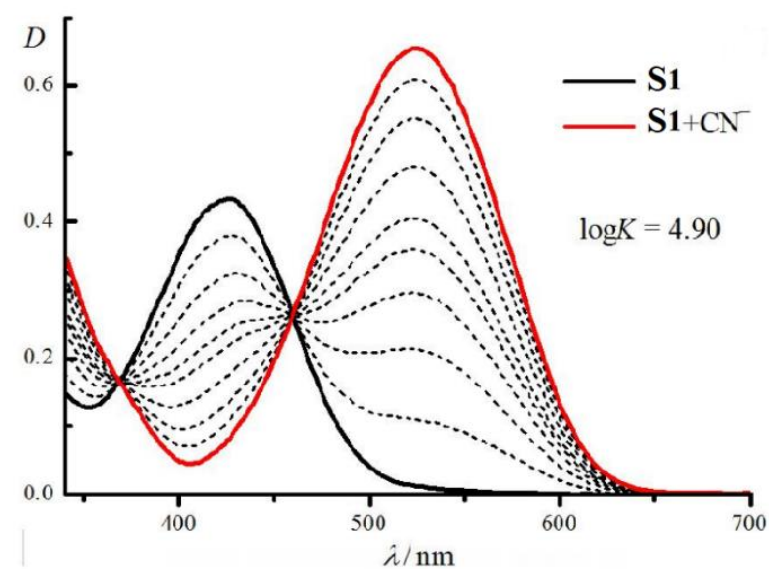

Рисунок 3 - ЭСП систем S1-ТБАСN (а) в МеCN (кювета 1 см): C(S1) = 4.4×10-5 M, концентрация ТБАСN варьировалась в диапазоне $0-4.7 \times 10-4 \mathrm{M}$ 
При этом в ходе спектрофотометрического титрования (СФТ) сохраняются изобестические точки, что говорит об образовании одного-единственного окрашенного продукта. Константу устойчивости комплекса красителя $\mathbf{S 1}$ с анионом $\mathrm{CN}^{-}$находили методом параметрического матричного моделирования [15]. Так, для 1-гидрокси-2-бензоиламино-9,10антрахинона (S1) $\lg K=4.90$. В случае 1-гидрокси-9,10-антрахинона добавление цианид-иона приводило к аналогичным спектральным изменениям, однако устойчивость комплекса оказалась существенно ниже $-\lg K=2.56$. Такое различие свидетельствует о влиянии бензоиламиногруппы на процесс взаимодействия лиганда $\mathbf{S 1}$ с $\mathrm{CN}^{-}$.

На основе сенсора S1 нами были изготовлены и испытаны колориметрические «тестполоски» для обнаружения $\mathrm{CN}$-ионов в $100 \%$-ном водном растворе (рисунок 4). Для построения цветовой шкалы определяемого иона были использованы растворы, содержащие цианиданионы в диапазоне концентраций от $10^{-8}$ до 1 М. Тест-полоски были приготовлены погружением фильтровальной бумаги «белая лента» в раствор соединения $\mathbf{S 1}$ в ДМСО, а затем высушены на воздухе. При погружении изготовленных тест-полосок, содержащих соединение S1, в водный раствор цианида цвет полосок мгновенно меняется из желтого в фиолетовый. Подобные тест-полоски могут быть использованы для обнаружения цианид-иона в воде.

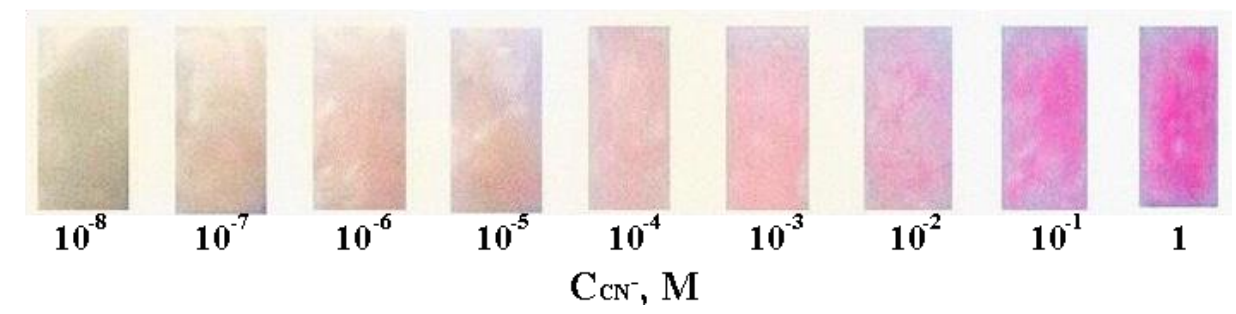

Рисунок 4 - Цветовая шкала для определения CN- с использованием бумажных тест-полосок

Таким образом, в результате проведенной работы был отобран образец $\mathbf{S 1}$, являющийся наиболее чувствительным и селективным реагентом на цианид-ионы в водных средах. Он структурно прост, устойчив к нагреву и воздуху и может быть легко приготовлен в одностадийной реакции из коммерчески доступных исходных материалов.

\section{Экспериментальная часть}

Растворители марки «хч» и «осч» использовали без дополнительной очистки. Соли ТБА фирмы «Sigma-Aldrich» использовали без дополнительной очистки.

Элементный анализ выполнен на приборе «vario MICRO cube». Электронные спектры поглощения измеряли на спектрофотометре «Lambda 35 UV/VIS» фирмы «PerkinElmer», coпряженном с ПК. Для записи спектров использовали кварцевые кюветы с длиной оптического пути $l=1$ см. ИК-спектры зарегистрированы на спектрофотометре «Spectrum One FT-IR» фирмы «PerkinElmer» в таблетках в $\mathrm{KBr}$ и в режиме МНПВО.

Спектры ЯMP ${ }^{1} \mathrm{H}$ и ${ }^{13} \mathrm{C}$ регистрировали на приборах «Bruker WP-200SY». Для записи спектров использовали растворы в $\mathrm{CDCl}_{3}$ и $\mathrm{DMSO}-\mathrm{d}_{6}$. Химические сдвиги (м.д.), приведены в шкале $\delta$, в качестве внутренних стандартов использовали сигналы растворителей.

Масс-спектры (ЭУ) получены на приборе «Finnigan MAT-8200» при ионизационном напряжении электронов 70 эВ, температура в камере ионизации 100-220 ${ }^{\circ} \mathrm{C}$. Приведены значения $\mathrm{m} / \mathrm{z}$ для молекулярного иона $[\mathrm{M}]^{+}$.

Для препаративной колоночной хроматографии использовали силикагель фирмы «Merck» с размером частиц 0.063-0.100 мм. Анализ TCX выполняли на пластинках «Silufol $\mathrm{UV}-254 »$. 


\section{Синтез 2-ациламинопроизводных 1-гидроксиантрахинона (S1-S4).}

\section{Общая методика}

Смесь (0.010 моль) 1-гидрокси-2-амино-9,10-антрахинона и (0.015 моль) соответствующего ацилирующего агента: бензоилхлорида, пентафторбензоилхлорида и ангидридов уксусной и трифторуксусной кислот в 100 мл толуола кипятят с обратным холодильником в течение 1 ч. до исчезновения исходного. Состав реакционной смеси контролируют с помощью ТСХ. Реакционную массу упаривают на ротационном испарителе до объема 4-5 мл и приливают серный эфир. Выпавший осадок отфильтровывают и промывают эфиром. Хроматографируют на $\mathrm{SiO}_{2}$, элюент - хлороформ. Собирают основную фракцию желтого цвета, содержащую целевой продукт.

1-гидрокси-2-бензоиламино-9,10-антрахинон (S1). Выделили 2.93 г (выход 76 \%). Т. пл. 217-218 ${ }^{\circ} \mathrm{C}$ (этанол-бензол). Спектр ЯМР ${ }^{1} \mathrm{H}\left(\mathrm{CDCl}_{3}, \delta\right.$, м.Д., J/Гц): 7.52 (м, 2Н, H-3',5'); 7.59 (м, 1H, H-4'); 7.78 (м, 2H, H-6,7); 7.91 (д, 1H, H-3, J=8.5); 7.94 (м, 2H, H-2',6'); 8.28 (м, 2H, Н-5,8);

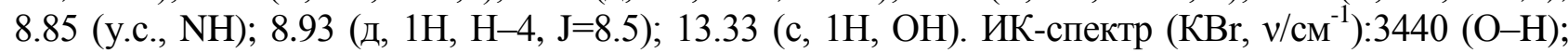
$3390(\mathrm{~N}-\mathrm{H}) ; 3065$ (аром. $\mathrm{C}-\mathrm{H}) ; 1688,1658(\mathrm{C}=\mathrm{O}) ; 1590$ (аром. $\mathrm{C}=\mathrm{C}$ ). Найдено (\%): $\mathrm{C}, 73.22 ; \mathrm{H}$, 3.38; N, 4.04. Вычислено для $\mathrm{C}_{21} \mathrm{H}_{13} \mathrm{NO}_{4}(\%)$ : C, 73.46; Н, 3.79; N, 4.08. М 343.

1-гидрокси-2-пентафторбензоиламино-9,10-антрахинон (S2). Выделили 3.11 г (72\%). Т. пл. $198-199{ }^{\circ} \mathrm{C}$ (этанол-бензол). Спектр ЯМР ${ }^{1} \mathrm{H}\left(\mathrm{CDCl}_{3}, \delta\right.$, м.д., J/Гц): 7.68 (м, 2Н, Н-6,7); 7.83 (д, $1 \mathrm{H}, \mathrm{H}-3, \mathrm{~J}=8.5$ ); 8.32 (м, 2H, H-5,8); 8.90 (д, 1H, H-4, J=8.5); 8.97 (у.с., $\mathrm{NH}$ ); 15.23 (с,

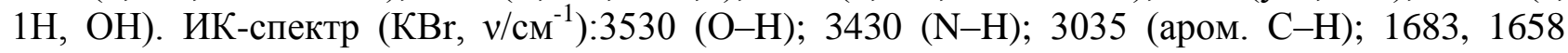
$(\mathrm{C}=\mathrm{O})$; 1590 (аром. C=C); 1256(C-F). Найдено (\%): C, 58.32; H, 1.68; F, 21.70; N, 3.04. Вычислено для $\mathrm{C}_{21} \mathrm{H}_{8} \mathrm{~F}_{5} \mathrm{NO}_{4}(\%): \mathrm{C}, 58.20 ; \mathrm{H}, 1.85 ; \mathrm{F}, 21.94 \mathrm{~N}, 3.23 . \mathrm{M} 433$.

1-гидрокси-2-ацетиламино-9,10-антрахинон (S3). Выделили 2.33 г (выход 83 \%). Т. пл. 202-203 ${ }^{\circ} \mathrm{C}$ (этанол-бензол). Спектр ЯМР ${ }^{1} \mathrm{H}\left(\mathrm{CDCl}_{3}, \delta\right.$, м.д., J/Гц): 2.19 (с, 3Н, $\left.\mathrm{COCH}_{3}\right) ; 7.69$ (м, 2H, H-6,7); 7.84 (д, 1Н, H-3, J=8.5); 8.35 (м, 2H, H-5,8); 8.82 (у.с., NH); 8.90 (д, 1Н, H-4, $\mathrm{J}=8.5) ; 13.15$ (с, 1H, OH). ИК-спектр (KBr, $\left./ \mathrm{cm}^{-1}\right)$ : $3450(\mathrm{O}-\mathrm{H}) ; 3370(\mathrm{~N}-\mathrm{H})$ 3065(аром. C-H); 2970, 2934 (алиф. $\mathrm{C}-\mathrm{H}$ ); 1750, $1670(\mathrm{C}=\mathrm{O}) ; 1595$ (аром. $\mathrm{C}=\mathrm{C}$ ). Найдено (\%): C, 68.48; Н, 3.74; $\mathrm{N}, 4.81$. Вычислено для $\mathrm{C}_{16} \mathrm{H}_{11} \mathrm{NO}_{4}(\%)$ : C, 68.33; H, 3.91; N, 4.98. M 281.

1-гидрокси-2-трифторацетиламино-9,10-антрахинона (S4). Выделили 2.75 г (82\%). $\mathrm{T}_{\text {пл }} 193-194^{\circ} \mathrm{C}$ (этанол-бензол). Спектр ЯМР ${ }^{1} \mathrm{H}\left(\mathrm{CDCl}_{3}, \delta\right.$, м.Д., Ј/Гц): 7.63 (м, 2H, H-6,7); 7.82 (д, 1H, H-3, J=8.5); 8.35 (м, 2H, H-5,8); 8.58 (д, 1H, H-4, J=8.5); 9.27 (у.с., NH); 17.23 (с, 1H,

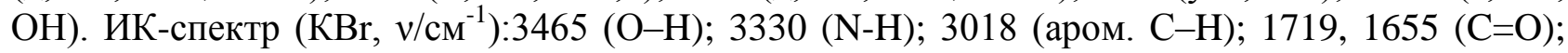
1590 (аром. $\mathrm{C}=\mathrm{C}$ ); 1129 (C-F). Найдено (\%): C, 58.32; Н, 1.68; F, 21.70; N, 3.04. Вычислено для $\mathrm{C}_{21} \mathrm{H}_{8} \mathrm{~F}_{5} \mathrm{NO}_{4}(\%): \mathrm{C}, 58.20 ; \mathrm{H}, 1.85 ; \mathrm{F}, 21.94 \mathrm{~N}, 3.23 . \mathrm{M} 433$.

\section{Спектрофотометрическое титрование (СФТ)}

Пример спектрофотометрического титрования. Вначале готовили концентрированные растворы солей ТБА: $\mathrm{CN}^{-}, \mathrm{F}^{-}, \mathrm{AcO}^{-}, \mathrm{H}_{2} \mathrm{PO}_{4}{ }^{-}, \mathrm{Cl}^{-}, \mathrm{Br}^{-}, \mathrm{I}^{-}, \mathrm{HSO}_{4}{ }^{-} \mathrm{NO}_{3}{ }^{-}$и $\mathrm{SCN}^{-}$в ацетонитриле. После чего готовили раствор лиганда в $\mathrm{MeCN}$ с концентрацией, рассчитанной на оптическую плотность 0.7 при измерении в кювете $l=1 \mathrm{~cm}$. Далее регистрировали изменения ЭСП после каждого добавления титранта (растворы солей ТБА) к раствору лиганда: 0 мкл, 20 мкл, 20 мкл, 50 мкл, 100 мкл, 200 мкл, 500 мкл и 1100 мкл. Прекращение изменений в ЭСП при последующем добавлении раствора означало конец титрования.

\section{Заключение}

Таким образом, в результате проведенной работы был отобран образец S1, являющийся наиболее чувствительным и селективным реагентом на цианид-ионы в водных средах. Он структурно прост, устойчив к нагреву и воздуху и может быть легко приготовлен в одностадийной реакции из коммерчески доступных исходных материалов. 


\section{Литература:}

1. Suksai, C. Chromogenic anion sensors / C. Suksai, T. Tuntulani // Chemical Society Reviews. - 2003. - Vol. 32. - P. 192-202.

2. Рецепторы анионов / Н. А. Ициксон [и др.] // Успехи химии. - 2008. - Т. 77 (9). C. 803-816.

3. Saini, R. Quinones based molecular receptors for recognition of anion and metal ions / R. Saini, N. Kaur, S. Kumar // Tetrahedron. - 2014. - Vol. 70. - P. 4285-4307.

4. Anion recognition and sensing in organic and aqueous media using luminescent and colorimetric sensors / T. Gunnlaugsson [et al.] // Coordination Chemistry Reviews. - 2006. - Vol. 250, iss. 23/24. - P. 3094.

5. Lieberzeit, P. A. Chemosensors in environmental monitoring: challenges in ruggedness and selectivity / P. A. Lieberzeit, F. L. Dickert // Analytical and Bioanalytical Chemistry. - 2009. Vol. 393. - P. 467-472.

6. Wang, B. Chemosensors: Principles, Strategies, and Applications / B. Wang, E. V. Anslyn. - Hoboken : John Wiley \& Sons, Hoboken, 2011. - 498 p.

7. Donagh, C. M. Optical Chemical Sensors / C. M. Donagh, C. S. Burke, B. D. MacCraith // Chemical Reviews. - 2008. - Vol. 108. - P. 400-422.

8. Fluorescent chemosensors: the past, present and future / T. Gunnlaugsson [et al.] // Chemical Society Reviews. - 2017. - Vol. 46, № 23. - P. 7105-7123.

9. Jackson, R. A review of rapid and field-portable analytical techniques for the diagnosis of cyanide exposure / R. Jackson, B. A. Logue // Analytica Chimica Acta. - 2017. - № 960. - P. 18-39.

10. Udhayakumari, D. Chromogenic and fluorogenic chemosensors for lethal cyanide ion. A comprehensive review of the year 2016 / D. Udhayakumari // Sensors and Actuators B: Chemical. - 2018. - Vol. 259. - P. 1022-1057.

11. Chemosensors: Principles, Strategies, and Applications. Eds E.V. Anslyn, B. Wang. Wiley, Hoboken, N.J. - 2011. -498 p.

12. Jayasudha, P. Highly selective colorimetric receptors for detection of fluoride ion inaqueous solution based on quinone-imidazole ensemble - Influence ofhydroxyl group / P. Jayasudha, R. Manivannan, K. P. Elango // Sensor and Actuators B: Chemical. - 2016. - Vol. 237. - P. 230238.

13. Saini, R. Quinones based molecular receptors for recognition of anion and metal ions / R. Saini, N. Kaur, S. Kumar // Tetrahedron. - 2014. - Vol. 70. - P. 4285-4307.

14. Файн, В. Я. 9,10-Антрахиноны и их применение / В. Я. Файн. - Москва : Центр фотохимии РАН, 1999. - 92 с.

15. Sandwich-Type Complexes of Alkaline-Earth Metal Cations with a Bisstyryl Dye Containing Two Crown Ether Units / E. N. Ushakov [et al.] // Journal of Physical Chemistry A. - 1999. Vol. 103. - P. 11188-11193. 